\title{
The interplay between exposure and preference for unpalatable foods by lambs
}

\author{
Juan Villalba $^{\mathrm{a}, *}$, Casey Spackman ${ }^{\mathrm{a}}$, Sandra Lobón ${ }^{\mathrm{b}}$ \\ ${ }^{a}$ Department of Wildland Resources, Quinney College of Natural Resources, Utah State University, Logan, UT, 84322, USA \\ ${ }^{\mathrm{b}}$ Department of Animal Production and Food Science, Veterinary School, University of Zaragoza, Zaragoza, 50013, Spain
}

\section{A R T I C L E I N F O}

\section{Keywords:}

Foraging behavior

Preference

Condensed tannins

Medusahead

Silica

Sheep

\begin{abstract}
A B S T R A C T
Herbivores satiate on single foods ingested too frequently or in excess. We hypothesized that exposure to the same unpalatable food too frequently or in excess causes satiety, which in turn would reduce subsequent use and preference for this food when alternatives become available. In each of three experiments, twenty-four lambs were randomly assigned to three treatment groups (8 lambs/group), where they received high (Ad libitum), intermediate $(100-200 \mathrm{~g} / \mathrm{d})$ or low exposure $(20-40 \mathrm{~g} / \mathrm{d})$ to three unpalatable foods: The invasive weed medusahead (Experiment 1), an alfalfa:quebracho tannin ration (70:30; QT) (Experiment 2), or wheat straw (Experiment 3). After exposure, all groups in Experiments 1 and 3 received a simultaneous offer of the unpalatable food and a novel food that changed across four consecutive preference tests: Grape pomace (Test 1), barley straw (Test 2), tall fescue hay (Test 3), and beet pulp (Test 4). Lambs in Experiment 2 received a simultaneous offer of each of these novel foods and the same novel food containing $30 \%$ quebracho tannins. During exposure, lambs in Experiment 1 showed a low and cyclic pattern of medusahead intake, and the group with intermediate level of medusahead exposure showed greater intake values than the Ad libitum group, followed by the group with the lowest level of exposure $(\mathrm{P}<0.05)$. For the rest of the experiments, intake was $A d$ libitum $>$ intermediate $>$ low level of exposure $(\mathrm{P}<0.05)$. During preference tests, lambs with the least level of exposure to the unpalatable foods tended to consume more medusahead ( $35 \%$ to $37 \%$; $\mathrm{P}=0.11$ ) or wheat straw (15 to $30 \% ; \mathrm{P}=0.10$ ) than lambs that received greater levels of exposure. In contrast, differential exposure to QT did not influence subsequent preference for tannin-containing foods $(\mathrm{P}=0.33)$, but animals with the greatest level of exposure to QT consumed 24\% more alternatives (i.e., non-tannin containing foods) than lambs that had received the lowest level of QT exposure $(\mathrm{P}<0.05)$. Intake of alternative novel foods during preference tests increased with increments in nutritional quality from grape pomace and barley straw to tall fescue hay and beet pulp $(\mathrm{P}<0.05)$, suggesting that lambs discriminated the nutritional value of the novel foods. In conclusion, repeated exposure to unpalatable foods has the potential to further reduce their utilization when alternatives -even when novel- become available. This effect appeared to be influenced by the chemical characteristics of the unpalatable food and it has implications for the coexistence of plant species in grazed communities.
\end{abstract}

\section{Introduction}

Ruminants evolved grazing on diverse arrays of plants with different physical and chemical characteristics, and in the process, they experienced different types and concentrations of nutrients and plant secondary compounds (PSC) (Robbins et al., 1995; Provenza et al., 2003). By consuming a mixed diet, herbivores obtain a balanced mix of nutrients (Westoby, 1978) that can dilute or inactivate PSC (Freeland and Janzen, 1974; Catanese et al., 2014), thus allowing for greater growth and reproduction (Rapport, 1980; Pennings et al., 1993). In contrast, an excessive or too frequent orosensorial and post-ingestive exposure to the same types and proportion of chemicals from the same food cause satiety (Provenza, 1996), and satiation on single foods may create mild to strong states of aversion due to excessive intake of toxins or to overconsumption of foods deficient in certain nutrients (Provenza, 1996; Distel and Villalba, 2018). Animals exposed too frequently or in too large a quantity to nutritionally imbalanced or toxic foods may satiate even more quickly and to a greater extent than when animals are consuming a nutritionally balanced ration (Provenza, 1996; Provenza and Villalba, 2006). The satiety hypothesis has been tested using

\footnotetext{
* Corresponding author.

E-mail address: juan.villalba@usu.edu (J. Villalba).
} 
different flavors (e.g., Early and Provenza, 1998; Atwood et al., 2001) or nutritious rations with (Mote et al., 2007) or without (Early and Provenza, 1998) PSC, but more studies are needed to explore the influence of satiety on preference for low-quality or nutritionally-imbalanced foods. It is also unknown whether repeated exposure to different nutritionally imbalanced foods or to PSC-containing foods yield similar levels of avoidance by herbivores.

Exposure to different levels of low-quality forages represents a common outcome for herbivores grazing on rangelands. For instance, medusahead (Taeniatherum caput-medusae (L.) Nevski) is an annual low-quality grass native to the Mediterranean region, which has invaded millions of acres in the Pacific Northwest, California, Utah and Nevada (Zimmerman et al., 2002). Grazing represents a sustainable, efficient, and low-cost alternative for medusahead control, but its low nutritional value and palatability constraints utilization by livestock (Murphy and Turner, 1959; Bovey et al., 1961). Medusahead avoidance increases grazing pressure on alternative, more palatable species, which confers this weed a competitive advantage in diverse plant communities (DiTomaso et al., 2008; Davy et al., 2009). An expansion in the abundance of medusahead also increases exposure, which, as explained above, may lead to a more pronounced avoidance of the weed due to satiation. Satiation on medusahead may create mild to strong states of food aversion that decrease subsequent intake and preference for this weed, creating a vicious cycle that contributes to its dominance in grazed plant communities. In support of this, prior research suggests that sheep grazing rangeland with low-levels of medusahead infestation (i.e., $5 \%$ of the plant community) consume medusahead in proportion to its availability (Montes-Sánchez et al. (2017)). However, when animals are offered ad libitum amounts of medusahead, they strongly avoid the weed and show very low levels of intake and preference (Hamilton et al., 2015; Villalba and Burritt, 2015). It is likely that in the former case, sheep do not satiate on medusahead due to the low abundance of the weed in the plant community, whereas in the latter case they satiate on the low-quality weed and display a high degree of avoidance.

In addition to low-quality forages like medusahead, some PSC like condensed tannins have anti-nutritional properties (Robbins et al., 1987) which may induce nutrient imbalances and promote after frequent or excessive exposure a state of avoidance, similar to those observed for low-quality foods. In support of this, previous research suggests that the relative amounts of PSC consumed by sheep affects subsequent intake and preference for PSC-containing foods (Mote el al., 2007). Thus, PSC-containing plants may satiate herbivores, creating a vicious cycle that increases grazing pressure on alternative, less defended or more palatable plants (e.g., see Bryant et al., 1991; Markó et al., 2008), as described for medusahead.

It was hypothesized that the level of exposure to low-quality foods (medusahead; wheat straw) or to a condensed tannin-containing food (i.e., unpalatable foods) would influence subsequent use of these foods by herbivores. Thus, it was predicted that lambs would decrease their intake and preference for unpalatable foods when these foods are available in ad libitum amounts, relative to when availability is restricted, as a consequence of a state of aversion induced by high levels of exposure. It was also predicted that such behavior would depend on the chemical composition of the unpalatable foods (i.e., low nutritional value $v s$. the presence of PSC in such foods) and on the nutritional quality of the food alternatives available for consumption.

\section{Materials and methods}

The study was conducted at the Green Canyon Ecology Center, located at Utah State University in Logan $\left(41^{\circ} 45^{\prime} 59^{\prime \prime} \mathrm{N}, 111^{\circ} 47^{\prime} 14^{\prime \prime} \mathrm{W}\right)$, according to procedures approved by the Utah State University Institutional Animal Care and Use Committee (IACUC Approval \#2521). Experiment 1 took place from June 1 to June 24, 2015, Experiment 2 from August 21 to September 10, 2015 and Experiment 3 from August 22 to September 8, 2016. For all experiments three sets of twenty-four commercial Finn-Columbia-Polypay-Suffolk crossbred lambs (4-6 months of age) of both sexes were individually penned outdoors, under a protective roof in individual, adjacent pens measuring $1.5 \times 2.5 \mathrm{~m}$ and fed ad libitum amounts of alfalfa pellets. Throughout the study, lambs had free access to fresh water and trace mineral salt blocks (mineral composition: minimum $96 \% \mathrm{NaCl}$, 320 mg/kg Zn, 380 mg/kg Cu, 2400 mg/kg Mn, 2400 mg/kg Fe, 70 mg/ $\mathrm{kg} \mathrm{I}$, and $40 \mathrm{mg} / \mathrm{kg} \mathrm{Co}$ ). All lambs were vaccinated against clostridium perfringens types $\mathrm{C} \& \mathrm{D}$ and tetanus toxoid ( $2 \mathrm{ml} / \mathrm{lamb})$, and they were dewormed with an oral drench of ivermectin $(0.2 \mathrm{mg} / \mathrm{kg} \mathrm{BW})$.

\subsection{General protocol}

\subsubsection{Exposure}

For each experiment, lambs were randomly assigned to three treatment groups (8 lambs/group) with restrictions of randomization on body weight (BW) and sex, such that all treatments were balanced for these variables. In experiment 1 , the three groups of lambs were exposed to different amounts of medusahead (ad libitum, 100 and $20 \mathrm{~g}$ / d). In experiment 2 , the groups were exposed to different amounts of ground alfalfa pellets containing 30\% quebracho tannins (ad libitum, 200 and $20 \mathrm{~g} / \mathrm{d}$ ), and in experiment 3 the three groups were exposed to different amounts of wheat straw (ad libitum, 100 and $20 \mathrm{~g} / \mathrm{d}$ ). During exposure, all lambs received alfalfa hay at levels that represented $3 \%$ BW.

\subsubsection{Preference tests}

After exposure, lambs in Experiments 1 and 3 were offered a choice between medusahead and an alternative novel feed. The alternative novel feed was changed every $2 \mathrm{~d}$ (grape pomace, barley straw, fescue hay, beet pulp). For experiment 2 , lambs were offered a choice between the novel feed (grape pomace, barley straw, fescue hay, beet pulp) and the same novel feed containing $30 \%$ quebracho tannins. The four novel feeds with and without condensed tannins were presented in consecutive choice tests as described for Experiments 1 and 2 .

After preference tests, all lambs were offered alfalfa hay such that each animal received an amount that represented 3\% BW.

\subsection{Foods}

In experiment 1, naturally established stands of medusahead (Taeniatherum caput-medusae (L.) Nevski) were harvested daily using a lawnmower (particle length of $5 \mathrm{~cm}$ ) from private property located in Paradise, Utah $\left(41^{\circ} 35^{\prime} 16^{\prime \prime} \mathrm{N}, 111^{\circ} 48^{\prime} 44^{\prime \prime} \mathrm{W}\right)$. Forage was then transported back to the Green Canyon Ecology Center for fresh offering. Medusahead was in the early reproductive stage with emergence of awns (during exposure) to emergence of seed head (during preference tests).

Grape (Vitis vinifera) pomace was in a ground $(0.5-1 \mathrm{~mm}$ particle size) state without stems.

Barley (Hordeum vulgare) was harvested in the autumn of 2014 and wheat in the autumn of 2015. The straws were passed through a hydraulic bale grinder (Gehl commercial forage grinder) and cut to a length of 1-4 mm particle size.

Endophyte-free tall fescue (E-, Lolium arundinaceum [Schreb.] Darbysh) hay was harvested in the vegetative phonological stage and baled in spring of 2014. The experimental hay was passed through a hydraulic bale grinder (Gehl commercial forage grinder) and cut to a length of 1-4 mm particle size.

Beet (Beta vulgaris) Pulp was in a pelleted state and subsequently passed through a shredder (Craftsman Model 987.799930) to obtain a particle size of $1-2 \mathrm{~mm}$.

Alfalfa (Medicago sativa) was in a pelleted form and subsequently passed through the shredder to obtain a particle size of 1-2 mm particle size. 
Table 1

Nutritional characteristics (\% of DM) of the foods used in the study.

\begin{tabular}{lllll}
\hline Food & $\begin{array}{l}\mathrm{CP}^{\mathrm{a}} \\
\% \mathrm{DM}\end{array}$ & $\mathrm{ADF}^{\mathrm{b}}$ & $\mathrm{NDF}^{\mathrm{c}}$ & $\mathrm{AIA}^{\mathrm{d}}$ \\
& & & & \\
\hline $\begin{array}{l}\text { Medusahead } \\
\quad \text { Exposure: June 1- }\end{array}$ & $10.2 \pm 0.7$ & $42.2 \pm 1.9$ & $66.1 \pm 0.2$ & $10.3 \pm 1.2$ \\
$\quad$ & & & & \\
$\quad \begin{array}{l}\text { June 6 } \\
\text { Medusahead }\end{array}$ & $9.3 \pm 0.1$ & $44.0 \pm 0.3$ & $66.0 \pm 1.2$ & $10.5 \pm 0.8$ \\
$\quad$ Exposure: June 11- & & & & \\
$\quad$ June 16 & & & & \\
$\begin{array}{l}\text { Medusahead } \\
\quad \text { Testing: June 17- }\end{array}$ & $8.0 \pm 0.5$ & $43.3 \pm 0.8$ & $62.5 \pm 1.4$ & $10.7 \pm 0.5$ \\
$\quad$ & & & & \\
$\quad$ June 24 & $17.0 \pm 0.3$ & $37.9 \pm 1.1$ & $44.3 \pm 1.1$ & $3.6 \pm 0.2$ \\
Alfalfa & $4.2 \pm 0.2$ & $46.8 \pm 2.0$ & $69.2 \pm 1.9$ & $5.2 \pm 0.4$ \\
Wheat Straw & $14.5 \pm 0.4$ & $53.7 \pm 1.4$ & $59.8 \pm 1.0$ & $1.7 \pm 0.1$ \\
Grape Pomace & & & & \\
Barley Straw & & & & \\
Tall Fescue & $4.6 \pm 0.5$ & $52.8 \pm 2.8$ & $73.0 \pm 2.6$ & $6.1 \pm 0.2$ \\
Beet Pulp & $10.6 \pm 0.3$ & $33.0 \pm 0.8$ & $51.5 \pm 1.2$ & $6.4 \pm 0.2$ \\
& $9.7 \pm 0.1$ & $25.1 \pm 0.5$ & $36.6 \pm 0.8$ & $1.8 \pm 0.1$
\end{tabular}

\footnotetext{
a Crude protein.

b Neutral detergent fiber.

c Acid detergent fiber.

d Acid insoluble ash.
}

\subsection{Experiment 1 (June 1-June 24, 2015) - Medusahead}

\subsubsection{Exposure (June 1-June 16)}

Twenty-four lambs of an average initial BW of $29.0 \pm 1.0 \mathrm{Kg} \mathrm{SE}$ were randomly assigned to three treatment groups that differed in the level of exposure to medusahead (8 lambs/group): (1) medusahead offered daily in ad libitum amounts; (2) medusahead $100 \mathrm{~g} / \mathrm{d}$; (3) medusahead $20 \mathrm{~g} / \mathrm{d}$ (Table 1). From 0900 to 1300 animals received their respective amounts of medusahead and ground alfalfa pellets, fed at $0.9 \%$ BW (amounts ranging from 164 to $324 \mathrm{~g}$ ). At 1300 refusals were collected and animals were then offered ground alfalfa pellets $(2.1 \%$ BW) to complete the daily offer to 3\% BW (amounts ranging from 382 to $756 \mathrm{~g}$ ). Refusals were collected at 17:00 and no other food was offered until the following day. After refusal collection intake of each food offered was determined for each animal. Exposure occurred during 16 consecutive $d$.

\subsubsection{Preference tests (June 17-June 24)}

Four different novel foods were presented in four consecutive choice tests that lasted $2 \mathrm{~d}$ each. From 0900-1300, all lambs received a simultaneous offer of ad libitum amounts of medusahead and: (1) grape pomace (Test 1: d1-2), (2) barley straw (Test 2: d3-4) (3), tall fescue hay (Test 3: d5-6), and (4) beet pulp (Test 4: d7-8) (Table 1).

\subsection{Experiment 2 (Aug 21-September 10, 2015) - condensed tannins}

\subsubsection{Exposure (Aug 21-Sept 2)}

A new set of twenty-four lambs with an average initial BW of $36.7 \pm 1.0 \mathrm{Kg}$ were randomly assigned to three treatment groups that differed in the level of exposure to ground alfalfa pellets uniformly mixed with $30 \%$ condensed tannins. Condensed tannins (in a powder form) were extracted from the South-American quebracho tree (Schinopsis quebracho-colorado; red quebracho) (Tannin Corp., Peabody, MA). Groups (8 lambs/group) were offered: (1) ad libitum amounts; (2) $200 \mathrm{~g} / \mathrm{d}$; and (3) $40 \mathrm{~g} / \mathrm{d}$ of the alfalfa-quebracho tannin mix. Exposure occurred daily from 0900 to 1300 . After refusal collection, intake was determined for each lamb and then each lamb received alfalfa pellets to complete a daily offer of alfalfa of $3 \%$ BW (amounts ranging from 737 to $1067 \mathrm{~g}$ ). Exposure occurred during 12 consecutive d.

\subsubsection{Preference tests (Sept 3-Sept 10)}

Lambs were offered a choice between ad libitum amounts of a novel food and the novel food containing 30\% quebracho tannins from 0900 to 1300 in four consecutive choice tests that lasted $2 \mathrm{~d}$ each. The four novel foods assayed were the same as those described in Experiment 1 and they were presented in the same order as described before: (1) grape pomace vs grape pomace:quebracho tannins (Test 1: d1-2), (2) barley straw $v$ s. barley straw:quebracho tannins (Test 2: d3-4), (3) tall fescue hay $v s$. tall fescue hay:quebracho tannins (Test 3: d5, 6), and (4) beet pulp vs beet pulp:quebracho tannins (Test 4: d7-8).

\subsection{Experiment 3 (August 22-September 8, 2016) - wheat straw}

\subsubsection{Exposure (August 22-August 31)}

A new set of twenty-four lambs of an average initial BW of $37.3 \pm 1.3 \mathrm{Kg} \mathrm{SE}$ were randomly assigned to three treatment groups that differed in the level of exposure to another low-quality food; wheat (Triticum aestivum L.) straw (8 lambs/group): (1) wheat straw offered in ad libitum amounts; (2) wheat straw $100 \mathrm{~g} / \mathrm{d}$; (3) wheat straw $20 \mathrm{~g} / \mathrm{d}$. From 0900 to 1300 animals received their respective amounts of straw and ground alfalfa pellets, fed at $0.9 \% \mathrm{BW}$ (amounts ranging from 245 to $490 \mathrm{~g}$ ). At 1300 refusals were collected and animals were then offered ground alfalfa pellets $(2.1 \% \mathrm{BW})$ to complete the daily offer to $3 \%$ BW (amounts ranging from 572 to $1144 \mathrm{~g}$ ). Refusals were collected at 17:00 and no other food was offered until the following day. After refusal collection intake of each food offered was determined for each animal. Exposure occurred during 10 consecutive d. After exposure, animals were offered ad libitum amounts of alfalfa pellets for 5 consecutive days.

\subsubsection{Preference tests (September 6-September 13)}

Four different novel foods were presented in four consecutive choice tests that lasted $2 \mathrm{~d}$ each as described in Experiment 1, except that wheat straw replaced medusahead.

\subsection{Chemical analyses}

Each day, representative samples of medusahead, grape pomace, barley straw, wheat straw, fescue hay, beet pulp and quebracho tannincontaining foods were placed in paper bags and dried in a forced-air oven at $60^{\circ} \mathrm{C}$ for $48 \mathrm{~h}$ to estimate dry matter content, in order to express intake values on a dry matter basis. Samples were ground using a $1 \mathrm{~mm}$ screen in a Wiley mill (Thomas Scientific, Swedensboro, NJ) and analyzed for dry matter (AOAC, 2000; Method 930.15), neutral detergent fiber (NDF), acid detergent fiber (ADF) (Van Soest et al., 1991), crude protein (CP) (AOAC, 2000; Method 990.03) and acid insoluble ash (Van Keulen and Young, 1977) as an estimate of silica content.

\subsection{Statistical analyses}

Food intake (DM basis, $\mathrm{g} / \mathrm{Kg} \mathrm{BW}$ ) during exposure and intake of medusahead, novel foods and novel foods with and without tannins during preference tests were analyzed as a split-plot design with lambs (random factor) nested within group. Group was the between-animal factor, and day (Exposure, preference tests) and preference test (1grape pomace, 2-wheat straw, 3-tall fescue hay, 4- beet pulp) were the repeated measures in the analyses (fixed factors). All analyses were computed using a mixed effects model (SAS version 9.4 for Windows; SAS Inst., Inc. Cary, NC). The variance-covariance structure used was the one that yielded the lowest Bayesian information criterion. The model diagnostics included testing for a normal distribution of the error residuals and homogeneity of variance. When normality or homocedasticity criteria were not met, data were transformed prior to analysis in order to stabilize the variance and to reduce skewness; nontransformed data are reported in the results section. Means were analyzed using pairwise differences of least squares means. 


\section{Results}

\subsection{Nutritional analyses}

Nutritional analyses for the foods used in the study are reported in Table 1. The concentration of CP in medusahead declined as the plant matured, from early exposure (June 1 to 6), towards testing (June 17 to 24 ), but the concentration of fiber in medusahead was similar across the same periods. The greatest concentrations of NDF and ADF were observed for barley and wheat straw and for grape pomace. On the other hand, the concentration of CP was the greatest for alfalfa hay, followed by grape pomace, and then by tall fescue hay, medusahead (early June) and beet pulp, foods that showed similar CP content ( $10 \%)$. In contrast, barley and wheat straw presented the lowest concentrations of $\mathrm{CP}$ (4.2 and 4.6\%). The concentration of acid insoluble ash was greater in medusahead than in the other foods assayed, with the lowest concentration in alfalfa, grape pomace and beet pulp.

\subsection{Experiment 1 - medusahead}

\subsubsection{Exposure}

As expected, different groups of lambs showed different levels of medusahead consumption during exposure (Group effect; $\mathrm{P}<0.0002$; Fig. 1A). However, the $100 \mathrm{~g} / \mathrm{d}$ Group showed the greatest average intake value of medusahead for the period $(0.32 \mathrm{~g} / \mathrm{Kg} \mathrm{BW})$, followed by the Ad libitum Group $(0.17 \mathrm{~g} / \mathrm{Kg} \mathrm{BW})$, and then by the group with the lowest level of exposure $(0.10 \mathrm{~g} / \mathrm{Kg} \mathrm{BW})(\mathrm{P}<0.05$; $\mathrm{SEM}=0.03 \mathrm{~g} / \mathrm{Kg}$ $\mathrm{BW}$ ). Intake of medusahead was cyclic across days (Day effect; $\mathrm{P}<0.0001$; Fig. 1A), and this pattern was more pronounced for the Ad libitum and $100 \mathrm{~g} / \mathrm{d}$ groups than for the group that received the lowest level of exposure to medusahead (Group $\mathrm{x}$ Day interaction; $\mathrm{P}<0.0001$; Fig. 1A).

\subsubsection{Preference tests}

Intake of medusahead was low across preference tests (Fig. 2A), but the group consuming the lowest amount of medusahead during exposure $(20 \mathrm{~g} / \mathrm{d})$, tended to show greater levels of medusahead intake during testing $(0.73 \mathrm{~g} / \mathrm{Kg} \mathrm{BW})$ than groups exposed to $100 \mathrm{~g} / \mathrm{d}(0.48 \mathrm{~g} /$ $\mathrm{Kg} \mathrm{BW})$ or to ad libitum amounts of the unpalatable food $(0.46 \mathrm{~g} / \mathrm{Kg} \mathrm{BW})$ (Group effect; $\mathrm{P}=0.110$; SEM $=0.12 \mathrm{~g} / \mathrm{Kg}$ BW; Fig. 2A). Such pattern was evident when the alternative food was barley straw (Test 2) or beet pulp (Test 4) (Group x Test; P = 0.09; Fig. 2A).

Medusahead intake across preference tests showed a decreasing trend as nutritional quality of the alternative novel foods increased from grape pomace (Test 1) and barley straw (Test 2) to tall fescue hay (Test 3) and beet pulp (Test 4): 0.8 and 0.7 to 0.2 and $0.5 \mathrm{~g} / \mathrm{kg} \mathrm{BW}$, respectively (Test effect; $\mathrm{P}=0.002$; $\mathrm{SEM}=0.1 \mathrm{~g} / \mathrm{kg}$ BW; Fig. $2 \mathrm{~A}$ ).

Intake of the alternative novel food during preference tests was much greater than intake of medusahead (Fig. 2B). Nevertheless, no differences among groups of lambs were detected for this variable (Group effect; $\mathrm{P}=0.335$; Group x Test; $\mathrm{P}=0.1652$; Fig. 2B). In contrast to consumption of medusahead, intake of the alternative food increased across testing, consistent with increments in nutritional quality of the alternative food in the choice test, from grape pomace (Test 1) and barley straw (Test 2) to tall fescue hay (Test 3) and beet pulp (Test 4): 7.0 and 5.0 to 9.7 and $22.1 \mathrm{~g} / \mathrm{kg} \mathrm{BW}$, respectively (Test effect; $\mathrm{P}<0.0001$; SEM $=0.7 \mathrm{~g} / \mathrm{kg}$ BW; Fig. 2B).

\subsection{Experiment 2 - condensed tannins}

\subsubsection{Exposure}

Groups differed in their intake of the tannin-containing food during exposure (Group effect; $\mathrm{P}<0.0001$; Fig. 1B). Average intake by group during the period was a function of the level of exposure to the tannincontaining food: Ad libitum $(9.9 \mathrm{~g} / \mathrm{Kg} \quad$ BW $)>200 \mathrm{~g} / \mathrm{d} \quad(4.4 \mathrm{~g} / \mathrm{Kg}$
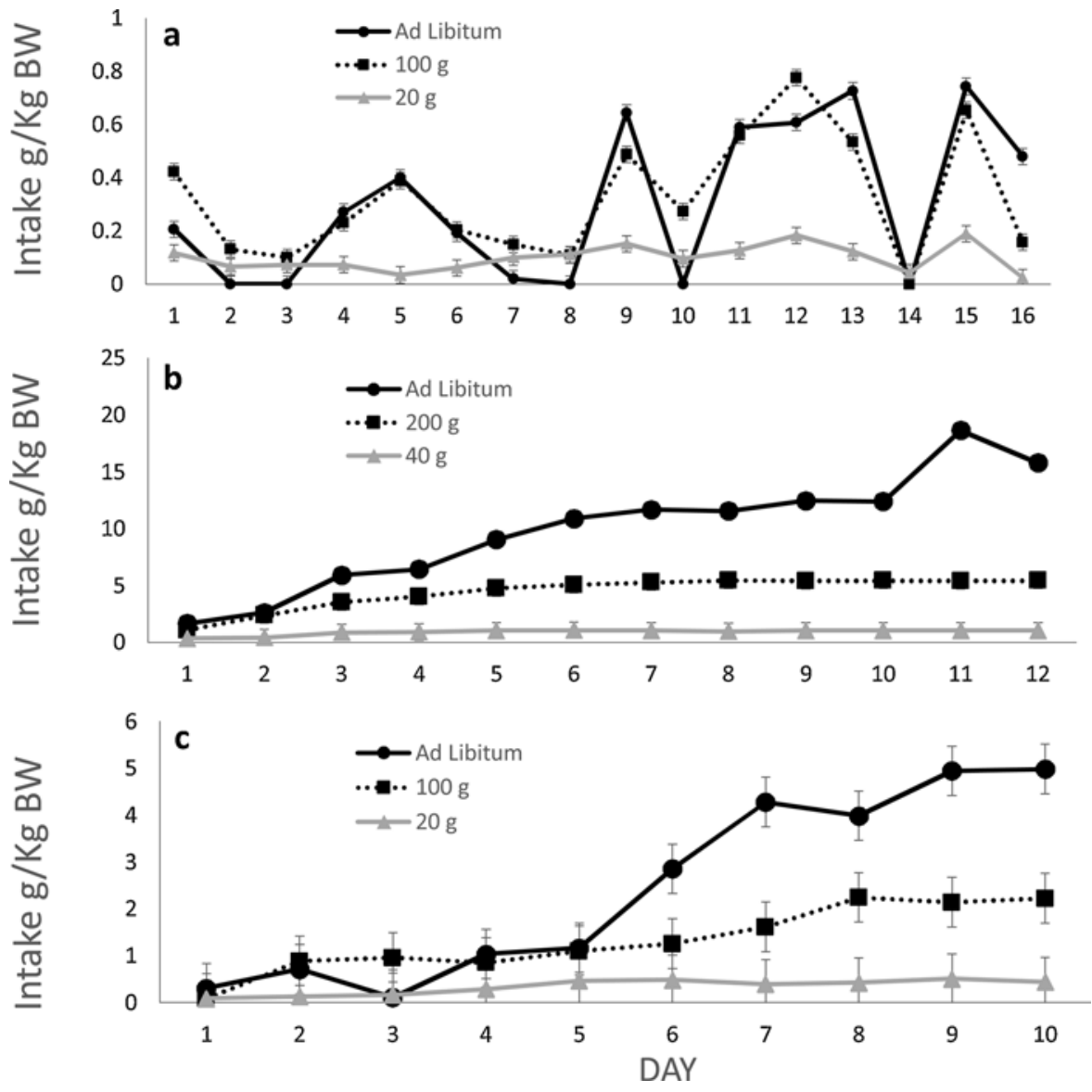

Fig. 1. Daily intake (expressed as $\mathrm{g} / \mathrm{kg}$ BW) of unpalatable foods by 3 groups of lambs $(\mathrm{N}=8)$ during a period of exposure. Lambs were exposed to the unpalatable food from 0900 to 1300 . (a.) Experiment 1. One group of lambs was offered ad libitum amounts of the unpalatable weed medusahead (group Ad libitum); the rest of the groups were exposed to daily offers of 100 or $20 \mathrm{~g}$ of medusahead. (b.) Experiment 2. One group of lambs was offered ad libitum amounts of an alfalfa:quebracho tannin ration (QT: 70:30) (group Ad libitum); the rest of the groups were exposed to daily offers of 200 or $40 \mathrm{~g}$ of QT, and (c.) Experiment 3. One group of lambs was offered ad libitum amounts of wheat straw (group Ad libitum); the rest of the groups were exposed to daily offers of 100 or $20 \mathrm{~g}$ of wheat straw. Values (with SEMs) are means for 8 lambs. 


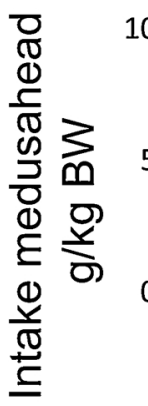

a

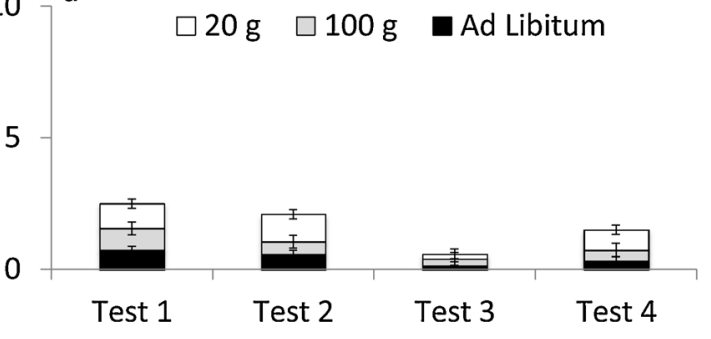

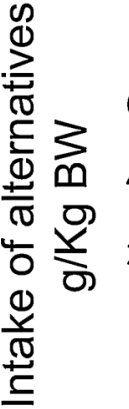

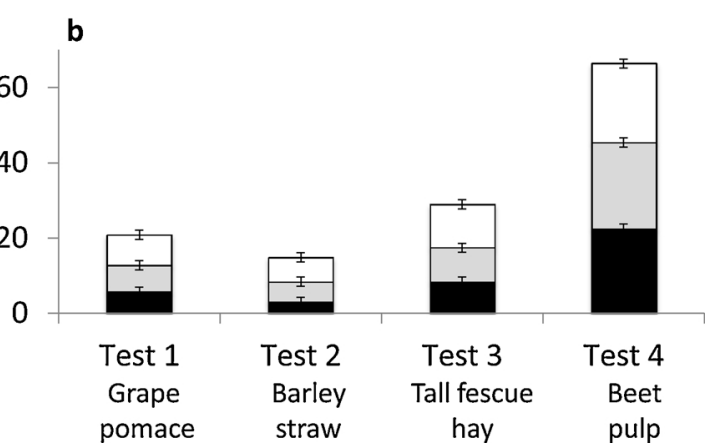

Fig. 2. Average intake (expressed as $\mathrm{g} / \mathrm{kg}$ ) of the unpalatable weed medusahead (panel a) and different food alternatives (panel b) during preference tests conducted after 3 groups of lambs were exposed to different amounts of medusahead. One group of lambs was exposed to ad libitum amounts of medusahead before testing (group Ad libitum); the remaining groups were previously exposed to daily offers of 100 or $20 \mathrm{~g}$ of medusahead. During each preference test, all lambs received a simultaneous offer of ad libitum amounts of medusahead and a novel food for 2 consecutive days from 0900 to 1300 . The alternative novel feed for each test was: Grape pomace (Test 1), barley straw (Test 2), tall fescue hay (Test 3), and beet pulp (Test 4). Bars (with SEMs) are means for 8 lambs/group.

BW $)>40 \mathrm{~g} / \mathrm{d}(0.9 \mathrm{~g} / \mathrm{Kg}$ BW $)(\mathrm{P}<0.0001 ; \mathrm{SEM}=0.54 \mathrm{~g} / \mathrm{Kg}$ BW $)$. Intake of the tannin-containing ration gradually increased for the $A d$ libitum group, but due to the lower level of exposure it remained stable for the other 2 groups (Day effect; Day x Group; P < 0.0001; Fig. 1B).

\subsubsection{Preference tests}

Intake of the tannin-containing novel foods did not differ among groups for the different preference tests assayed (Group effect; $\mathrm{P}=0.33$; Group $\mathrm{x}$ Test; $\mathrm{P}=0.17$; Fig. $3 \mathrm{~A}$ ). However, intake of the tannin-containing foods varied across preference tests with the greatest intakes observed for tannin-containing grape pomace (Test $1 ; 10.13 \mathrm{~g} /$ $\mathrm{Kg} \mathrm{BW})>$ tannin-containing tall fescue (Test 3; $4.29 \mathrm{~g} / \mathrm{Kg} \mathrm{BW}$ ) $>$ tannin-containing barley straw (Test $2 ; 1.50 \mathrm{~g} / \mathrm{Kg} \mathrm{BW}$ ) $=$ tannin-containing beet pulp (Test $4 ; 1.95 \mathrm{~g} / \mathrm{Kg}$ BW; SEM $=0.77 \mathrm{~g} / \mathrm{Kg} \quad \mathrm{BW}$; $\mathrm{P}<0.0001$; Fig. 3A).

Intake of the alternative novel foods (i.e., non-tannin containing foods) during preference tests differed among groups (Group effect; $\mathrm{P}=0.04$; Fig. 3B). The Ad libitum group ingested more non-tanning containing food $(12.1 \mathrm{~g} / \mathrm{Kg} \mathrm{BW})$ than the group with the lowest exposure to condensed tannins $(9.2 \mathrm{~g} / \mathrm{Kg}$ BW; SEM $=0.75 \mathrm{~g} / \mathrm{Kg} \mathrm{BW}$; $\mathrm{P}=0.01$ ) and tended to consume more non-tannin containing food than the group with the intermediate level $(200 \mathrm{~g} / \mathrm{d})$ of exposure $(10.9 \mathrm{~g} / \mathrm{Kg} \mathrm{BW} ; \mathrm{SEM}=0.75 \mathrm{~g} / \mathrm{Kg} \mathrm{BW} ; \mathrm{P}=0.12)$. Intake of the nontannin containing foods increased across tests with the lowest intakes observed for Test 1 (grape pomace) and the greatest intakes for beet pulp (Test 4; Test effect; $\mathrm{P}<0.0001$; Fig. 3B).
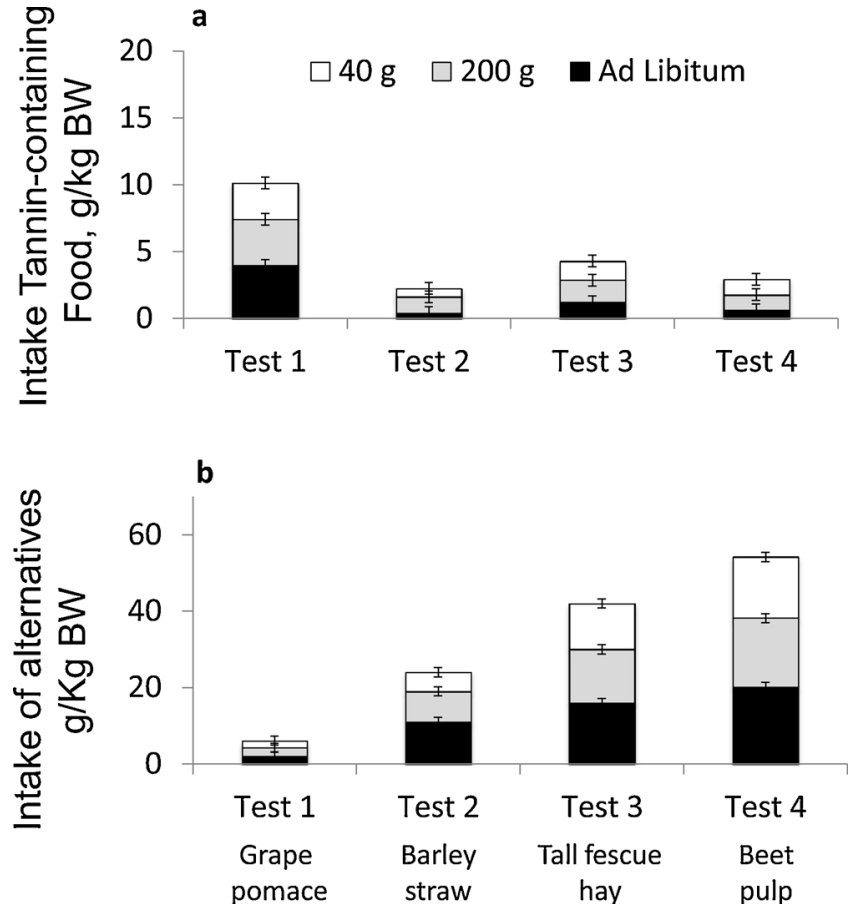

Fig. 3. Average intake (expressed as $\mathrm{g} / \mathrm{kg}$ ) of a novel food containing $30 \%$ quebracho tannins (panel a) and the same food without quebracho tannins (panel b) during preference tests conducted after 3 groups of lambs were exposed to different amounts of quebracho tannins. One group of lambs was exposed to ad libitum amounts of an alfalfa:quebracho tannin ration (70:30; QT) before testing (group Ad libitum); the remaining groups were previously exposed to daily offers of 200 or $40 \mathrm{~g}$ of QT. During each preference test, all lambs received a simultaneous offer of ad libitum amounts of a novel food containing $30 \%$ quebracho tannins and the same novel food without quebracho tannins for 2 consecutive days from 0900 to 1300 . The novel food for each test was: Grape pomace (Test 1 ), barley straw (Test 2), tall fescue hay (Test 3 ), and beet pulp (Test 4). Bars (with SEMs) are means for 8 lambs/group.

\subsection{Experiment 3 - wheat straw}

\subsubsection{Exposure}

As expected, different groups of lambs showed different levels of wheat consumption during exposure (Group effect; $\mathrm{P}=0.001$; Fig. 1C). Average intake by group during the period was a function of the level of exposure to straw: Ad libitum $(2.4 \mathrm{~g} / \mathrm{Kg} \mathrm{BW})>100 \mathrm{~g} / \mathrm{d}(1.3 \mathrm{~g} / \mathrm{Kg} \mathrm{BW}$; $\mathrm{P}<0.05)>20 \mathrm{~g} / \mathrm{d}(0.3 \mathrm{~g} / \mathrm{Kg} \mathrm{BW})(\mathrm{P}=0.05 ; \mathrm{SEM}=0.34 \mathrm{~g} / \mathrm{Kg} \mathrm{BW})$. Intake of wheat straw was similar among groups during the first $5 \mathrm{~d}$ of exposure, when intakes diverged as a function of the level of exposure designed for each group (Day effect; Group x Day; $\mathrm{P}<0.0001$; Fig. 1C).

\subsubsection{Preference tests}

Intake of wheat straw was low across preference tests (Fig. 4A), but the group consuming the lowest amount of wheat straw during exposure $(20 \mathrm{~g} / \mathrm{d})$, tended to show greater levels of straw intake $(4.6 \mathrm{~g} / \mathrm{Kg}$ BW) than the groups exposed to $100 \mathrm{~g} / \mathrm{d}(3.2 \mathrm{~g} / \mathrm{Kg} \mathrm{BW})$ or to ad libitum amounts of the unpalatable food $(3.9 \mathrm{~g} / \mathrm{Kg} \mathrm{BW}$ ) (Group effect; $\mathrm{P}=0.10$; $\mathrm{SEM}=0.62 \mathrm{~g} / \mathrm{Kg}$ BW; Fig. 4A).

Wheat straw intake across preference tests showed a decreasing trend as nutritional quality of the alternative novel foods increased from grape pomace (Test 1 ) and barley straw (Test 2) to tall fescue hay (Test 3) and beet pulp (Test 4): 6.3 and 4.6 to 3.7 and $1.1 \mathrm{~g} / \mathrm{kg} \mathrm{BW}$, respectively (Test effect; $\mathrm{P}<0.0001 ; \mathrm{SEM}=0.49 \mathrm{~g} / \mathrm{kg} \mathrm{BW}$; Fig. 4A).

No differences among groups of lambs were observed for the consumption of alternative foods during choice tests (Group effect; $\mathrm{P}=0.644$; Group $\mathrm{x}$ Test; $\mathrm{P}=0.522$; Fig. 4B). Intake of barley straw 


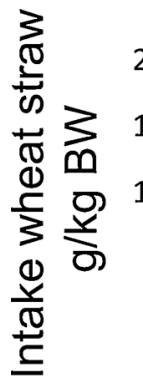

\section{a}

$\left.\begin{array}{c}20 \\ 15 \\ 10 \\ 5 \\ 0\end{array}\right]$

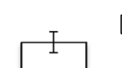

$\square 20 \mathrm{~g}$

$\square 100 \mathrm{~g}$

Ad Libitum

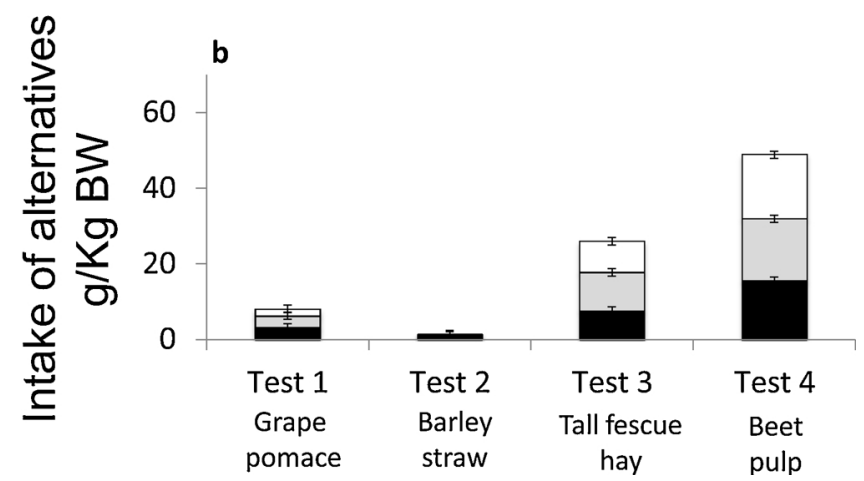

Fig. 4. Average intake (expressed as $\mathrm{g} / \mathrm{kg}$ ) of wheat straw (panel a) and different food alternatives (panel b) during preference tests conducted after 3 groups of lambs were exposed to different amounts of wheat straw. One group of lambs was exposed to ad libitum amounts of wheat straw before testing (group Ad libitum); the remaining groups were previously exposed to daily offers of 100 or $20 \mathrm{~g}$ of wheat straw. During each preference test, all lambs received a simultaneous offer of ad libitum amounts of wheat straw and a novel food for 2 consecutive days from 0900 to 1300 . The alternative novel food for each test was: Grape pomace (Test 1), barley straw (Test 2), tall fescue hay (Test 3), and beet pulp (Test 4). Bars (with SEMs) are means for 8 lambs/group.

during preference tests (Test 2) was particularly low $(0.48 \mathrm{~g} / \mathrm{Kg} \mathrm{BW})$, but lambs increased their consumption of the alternative food as the nutritional quality of the novel food increased from grape pomace and barley straw to tall fescue hay and beet pulp (Test effect; P $<0.0001$; $\mathrm{SEM}=0.56 \mathrm{~g} / \mathrm{kg}$ BW; Fig. 4B).

\section{Discussion}

We hypothesized that repeated exposure to unpalatable foods by lambs would reduce preference for such foods in ensuing choice tests because herbivores develop transitory aversions for food just eaten as a result of sensory input (i.e., orosensorial experiences) and postingestive effects (i.e., effects of nutrients and toxins in the internal environment) unique to each food (Provenza, 1996). Repeated or excessive exposure to the same oro-sensorial stimulation triggers satiety, i.e., sensory-specific satiety (Rolls et al., 1982), a term used to refer to the decrease in preference for the taste of food after it has been eaten to satiety. Regarding post-ingestive effects, exposure to nutritionally imbalanced foods (Heeley and Blouet, 2016) or to PSC-containing foods (Provenza et al., 1990) also reduce preference, in this case triggered by the negative consequences that those foods promote in the internal environment (Provenza, 1996). Consistent with these ideas, lambs with the least level of exposure to medusahead (i.e., $20 \mathrm{~g} / \mathrm{d}$ ) consumed 35\% more medusahead in ensuing choice tests than lambs exposed to greater amounts (i.e., Ad libitum, $100 \mathrm{~g} / \mathrm{d}$ ). Nevertheless, the amount of medusahead consumed by lambs was low, even when the alternative novel food presented during preference tests was of low nutritional quality (e.g., barley straw, grape pomace). Grape pomace had 13\% CP but the majority of this protein (70-88\%) is resistant to digestion since lignin, tannins and other polyphenols in grape pomace form complexes with protein, reducing its availability (Saura-Calixto et al., 1991; Yu and Ahmedna, 2013). Similarly, lambs offered the lowest amount of wheat straw during exposure $(20 \mathrm{~g} / \mathrm{d})$, consumed between 15 and $30 \%$ more straw during preference tests than lambs previously exposed to greater amounts (i.e., Ad libitum, $100 \mathrm{~g} / \mathrm{d}$ ). In contrast to medusahead and to wheat straw (e.g., low-quality foods), different levels of exposure to condensed tannins did not yield different levels of tannin use during ensuing preference tests. Nevertheless, animals with the greatest level of exposure to condensed tannins (the Ad libitum group) consumed between 10 and $24 \%$ more alternatives (i.e., non-tannin containing foods) during preference tests than lambs that received lower levels of exposure to this PSC. Thus, even when the level of exposure to unpalatable foods influenced subsequent preference, the pattern emerging in preference tests depended on the chemical characteristics of the unpalatable food.

\subsection{Preference as influenced by exposure to different unpalatable foods}

The pattern of intake of the unpalatable foods assayed during this study was different during exposure. Intake of the low-quality weed medusahead was cyclic and low, whereas intake of wheat straw, another low-quality food, was greater and more consistent across days. In addition, medusahead is low in nutrients with high concentration of the anti-nutritional component silica, involved in the reduction of preference for grasses by herbivores to the extent of being considered a plant defense (Hunt et al., 2008; Hartley and DeGabriel, 2016). Silica is present at high concentrations (10-12\%; Hamilton et al., 2015; Montes Sanchez and Villalba, 2017a, Montes-Sánchez and Villalba, 2017b) on the epidermis of medusahead, acting as a physical barrier that prevents microbial attachment and/or colonization of plant cell walls and thus enzymatic degradation of structural carbohydrates (Van Soest and Jones, 1968; Mayland and Shewmaker, 2001; Van Soest, 2006). This process delays the rate of passage of plant material through the digestive tract, which reduces intake and explains the cyclic pattern of medusahead intake by sheep across days (Montes Sanchez and Villalba, 2017a, Montes-Sánchez and Villalba, 2017b). The concentration of acid insoluble ash, an indicator of silica in the plant (Van Keulen and Young, 1977), in the present study was in the $10 \%$ range and thus consistent with values reported in previous studies (Hamilton et al., 2015; MontesSánchez and Villalba (2017a); Montes-Sánchez and Villalb (2017)b).

Animals decrease food intake when they receive the same chemosensorial stimulation or chemo-sensorial stimulation that match the supply of intragastric infusions of non-nutritive solutions (Rolls, 1986). This response is explained by sensory-specific satiety and by the lack of post-ingestive feedback from nutrients that typically stimulates feeding (Provenza, 1996). Thus, the slow availability of nutrients derived from medusahead digestion due to silica, coupled with its low nutritional value may produce very weak positive post-ingestive feedback signals that do not encourage further consumption of this weed, and in particular when exposure is increased as observed in this study for the $A d$ libitum group. In fact, the group with intermediate levels of exposure $(100 \mathrm{~g} / \mathrm{d})$ showed greater intake values of medusahead during exposure than the Ad libitum Group, suggesting that animals with the greatest availability of medusahead developed a greater level of avoidance to the weed than those constrained to lower amounts. In contrast, animals exposed to wheat straw consumed the low-quality food in proportion to its availability without the cyclic pattern of intake observed for medusahead. It is likely that a more extensive digestion of cell walls in wheat straw led to a greater supply of nutrients that reduced the level of avoidance relative to medusahead. Wheat straw presents lower levels of silica (1-5\%; Van Soest, 2006; 5.2\% AIA in this study) than medusahead, which allows for greater degradability of plant material and thus the supply of nutrients to the animal (Montes Sanchez and Villalba, 2017a, Montes-Sánchez and Villalba, 2017b). Consistent with this, intake during exposure and testing was much greater for wheat straw than for medusahead (Figs. 1, 3 and 4). In addition, the reduction in 
intake of the unpalatable food by the Ad libitum group relative to the $20 \mathrm{~g} / \mathrm{d}$ group during preference tests was greater in the medusahead than in the wheat straw study ( $37 \%$ vs. $15 \%$ reduction).

Exposure to the tannin-containing food had a different impact on preference from that observed for medusahead or wheat straw. Prior exposure to quebracho tannins only influenced intake of food alternatives in choice tests, with lambs exposed to ad libitum amounts of the tannin-containing ration ingesting more non-tanning containing food than groups with lower levels of exposure. Plant secondary compoundcontaining foods can induce strong and persistent aversions in ruminants, which result from stimulation of the emetic system of the midbrain and brain stem (Provenza, 1996). Naïve goats learn to limit the intake of the current-season's twigs of a shrub (Coleogyne ramosissima) that contain high levels of condensed tannins within a short period of time (1 h), causing a strong state of aversion (Provenza et al., 1990). Such negative experience modifies the feeding behavior of goats in a manner that animals prefer to eat older growth twigs of the shrub, which are lower in nutrients than young twigs, but older twigs are also lower in the condensed tannins that caused malaise. In addition, PSCs like quebracho tannins can cause tissue damage adversely affecting animal health (Hervás et al. (2003)), which promotes negative postingestive effects that likely lead to stronger states of avoidance than those induced from ingesting low-quality foods. Such stronger states of avoidance may help explain the fact that intake of quebracho tannin during choice tests was independent of the prior level of tannin exposure. In addition, condensed tannins cause astringency (Glendinning (1994)), which could have also triggered negative affective responses even at the lowest level of tannin exposure - that were independent of the level of tannin ingested by the different groups of lambs. In summary, our results suggest that prior exposure to unpalatable foods reduce preference for such foods, but the decline is dependent upon the type food consumed. Intake of low-quality foods during preference tests appeared to be influenced by prior level of exposure (e.g., low vs. high) and by the chemistry of the food (e.g., medusahead $v s$. wheat straw). Intake of PSC-containing foods during preference tests was independent of the level of exposure to such foods, likely due to a stronger state of avoidance triggered by the orosensorial and postingestive effects of PSC, but intake of alternatives (i.e., novel foods without tannins) was greater with prior ad libitum exposure to tannin-containing foods.

\subsection{Preference for alternatives}

Intake of the alternative food during preference tests was in general greater than intake of medusahead or wheat straw and -in contrast to medusahead or wheat straw - it showed an increasing trend with increments in nutritional quality from grape pomace and barley straw to tall fescue hay and beet pulp. Lambs displayed such ingestive patterns despite the fact that alternative foods were novel. Likewise, lambs increased their intake of non-tannin containing foods as the quality of these alternatives increased. Sheep form preferences for foods that provide required nutrients and preference increases as the nutrient rewards increase (Villalba and Provenza, 2000a). In addition, herbivores use visual and olfactory cues to recognize specific plants (Launchbaugh and Provenza, 1993), and they generalize their preferences from familiar to unfamiliar foods based on common flavor cues (Villalba and Provenza, 2000b). Thus, flavor generalization increases the acceptance of novel nutritious foods (Launchbaugh et al., 1997), representing a mechanism that enhances the efficiency of incorporation of novel nutritious foods into an herbivore's diet. The trend for consumption of novel foods in proportion to their nutritional quality in this study could thus be explained by generalization over familiar flavor cues present in the novel foods. Lambs were familiar with alfalfa and they were exposed to barley and corn when they were reared with their mothers, so even when limited, lambs in this study had experience with nutritious foods and cues that could have been generalized to the novel foods offered in choice tests. In support of this idea, sheep and goats prefer novel hays sprayed with organic solvent extracts from herbage and energy concentrates (Dohi et al., 1996; Dohi and Yamada, 1997).

\subsection{Implications for intake of unpalatable plants in natural settings}

Generalist herbivores evolved grazing plant assemblages with a diversity of nutrients, PSC and sensorial cues (Provenza et al., 2003). Such diversity is also manifested by the presence of unpalatable plants low in nutrients and with antinutritional factors coexisting with species of greater nutritional quality. A characteristic for ruminants grazing such diverse array of plant species involves animals preferentially selecting one species over another, achieving an uneven use of resources in the community. For instance, livestock display low preference for medusahead during grazing, which increases grazing pressure on palatable native plants, increasing the competitive ability of the weed and its spread- across landscapes (George et al., 1989; Young, 1992). Our results suggest that this expansion could create a vicious cycle as animals with increased exposure to medusahead (i.e., due to increments in abundance) may further reduce its utilization due to sensorial and postingestive satiety. This scenario was represented in the present study with the Ad libitum group, where access to nutritious alfalfa was kept constant during exposure $(0.9 \% \mathrm{BW})$-mimicking a restricted amount of palatable native plants in the community, with unlimited availability of medusahead. This level of exposure was contrasted with conditions where the abundance of the unpalatable plant in the feeding environment was constrained (e.g., $100 \mathrm{~g} / \mathrm{d} ; 20 \mathrm{~g} / \mathrm{d})$ at the same level of alfalfa availability. Under these conditions, lambs in the Ad libitum group tended to reduce their preference for medusahead. This pattern of reduced proportional utilization of the unpalatable food as abundance of the unpalatable food increases could also be expected in other plants of low nutritional quality in the community, similar to wheat straw. Nevertheless, and as stated before, the reduction in utilization of the unpalatable food as a function of exposure in this study (Ad libitum vs. $20 \mathrm{~g} / \mathrm{d}$ ) appeared to be more pronounced for medusahead than for wheat straw, likely due to the foods' different chemistries. In contrast, plant communities invaded by some PSC-containing plants (e.g., condensed tannins with a chemistry similar to those presented by quebracho tannins) may not be affected by prior level of exposure in the same manner observed for low-quality plants. In this case, enhanced exposure to PSC may increase grazing pressure on alternatives, which also confers competitive advantage to PSC-defended plants.

Evidence that proportionate intake of individual plants increases as the biomass of the plant declines in the community has been suggested for different ecosystems (Provenza et al., 2003) and it has been derived from functional response models that incorporate the idea of satiety described in this study (Li et al., 2006). For instance, browsing of saplings of woody species by snowshoe hares is most severe when these species are rare (Provenza et al., 2003) and livestock use unpalatable shrubs to a greater extent when these shrubs are scarcely distributed in the landscape, whereas use declines in dense stands (Heady, 1964).

\section{Conclusion}

Herbivore selectivity may enhance the dominance of less palatable plant species in grassland ecosystems. This study suggests that repeated exposure to unpalatable plant species has the potential to further reduce their utilization in the plant community or increase grazing pressure on alternatives. Thus, prior exposure represents another variable, in addition to other biotic and abiotic factors, that may constrain the utilization of abundant low-quality forages and contribute to the dominance of these unpalatable species in grazed landscapes.

\section{Conflicts of interest}

The authors declare no conflicts of interest.

The work described has not been published previously and it is not 
under consideration for publication elsewhere.

\section{Role of the funding source}

Institutions that provided funding had no involvement in the collection, analysis or interpretation of data.

\section{Acknowledgements}

This research was supported by grants from the United States Department of Agriculture, National Institute of Food and Agriculture, USDA-NIFA (grant number 2011-38415-31187) and the Utah Agricultural Experiment Station (grant number 1321). This paper was published with the approval of the Director, Utah Agricultural Experiment Station, and Utah State University, as journal paper number 9138.

\section{References}

AOAC, 2000. Official methods of analysis. Association of Official Analytical Chemists, 17th edn. Perkin Elmer 5300 DV ICP. Perkin Elmer, 710 Bridgeport Avenue, Shelton, CT.

Atwood, S.B., Provenza, F.D., Wiedmeier, R.D., Banner, R.E., 2001. Changes in preferences of gestating heifers fed untreated or ammoniated straw in different flavors. J. Anim. Sci. 79, 3027-3033.

Bovey, R.W., Le Tourneau, D., Erickson, L.C., 1961. The chemical composition of medusahead and downy brome. Weeds 9, 307-311.

Bryant, J.P., Provenza, F.D., Pastor, J., Reichardt, P.B., Clausen, T.P., du Toit, J.T., 1991. Interactions between woody plants and browsing mammals mediated by secondary metabolites. Annu. Rev. Ecol. Evol. Syst. 22, 431-446.

Catanese, F., Distel, R.A., Villalba, J.J., 2014. Effects of supplementing endophyte-infected tall fescue with sainfoin and polyethylene glycol on the physiology and ingestive behavior of sheep. J. Anim. Sci. 92, 744-757.

Davy, J., Laca, E.A., Forero, L., 2009. Medusahead: what is being tested to reduce it. Northern California Ranch Update 3.

Distel, R.A., Villalba, J.J., 2018. Use of unpalatable forages by ruminants: the influence of experience with the biophysical and social environment. Animals 8, 56.

DiTomaso, J.M., Kyser, G.B., George, M.R., Doran, M.P., Laca, E.A., 2008. Control of medusahead (Taeniatherum Caput-Medusae) using timely sheep grazing. Invasive Plant Sci. Mana. 1, 241-247.

Dohi, H., Yamada, A., 1997. Preference of sheep and goats for extracts from high-grain concentrate. J. Anim. Sci. 75 (2073), 2077.

Dohi, H., Yamada, A., Fukukawa, T., 1996. Effects of organic solvent extracts from her bage on feeding behavior in goats. J. Chem. Ecol. 22, 425-430.

Early, D.M., Provenza, F.D., 1998. Food flavor and nutritional characteristics alter dynamics of food preference in lambs. J. Anim. Sci. 76, 728-734.

Freeland, W.J., Janzen, D.H., 1974. Strategies in herbivory by mammals the role of plant secondary compounds. Am. Nat. 108, 269-289.

George, M., Knight, R., Sands, P., Demment, M., 1989. Intensive grazing increases beef production. Calif. Agric. 43, 16-19.

Glendinning, J.I., 1994. Is the bitter rejection response always adaptive? Physiol. Behav. $56,1217-1227$

Hamilton, T., Burritt, E.A., Villalba, J.J., 2015. Assessing the Impact of supplements, food aversions, and silica on medusahead (Taeniatherum caput-Medusae (L.) Nevski) use by sheep. Small Rumin. Res. 124, 45-54.

Hartley, S.E., DeGabriel, J.L., 2016. The ecology of herbivore-induced silicon defences in grasses. Flora - Morphol. Distrib. Funct. Ecol. Plants 30, 1311-1322.

Heady, H.F., 1964. Palatability of herbage and animal preference. J. Range. Manage. 17, 76-82.

Heeley, N., Blouet, C., 2016. Central amino acid sensing in the control of feeding behavior. Front. Endocrinol. 7, 148

Hervás, G., Pérez, V., Giráldez, F.J., Mantecón, A.R., Almar, M.M., Frutos, P., 2003. Intoxication of sheep with quebracho tannin extract. J. Comp. Pathol. 129, 44-54.

Hunt, J.W., Dean, A.P., Webster, R.E., Johnson, G.N., Ennos, A.R., 2008. A novel mechanism by which silica defends grasses against herbivory. Ann. Bot. 102, 653-656.

Launchbaugh, K.L., Provenza, F.D., 1993. Can plants practice mimicry to avoid grazing by mammalian herbivores? Oikos 66, 501-504.

Launchbaugh, K.L., Provenza, F.D., Werkmeister, M.J., 1997. Overcoming food neophobia in domestic ruminants through addition of a familiar flavor and repeated exposure to novel foods. Appl. Anim. Behav. Sci. 54, 327-334.

Li, Y., Feng, Z., Swihart, R., Bryant, J., Huntly, N., 2006. Modeling the impact of plant toxicity on plant-herbivore dynamics. J. Dyn. Differ. Equ 18, 1021-1042.

Markó, G., Gyuricza, V., Bernáth, J., Altbacker, V., 2008. Essential oil yield and composition reflect browsing damage of junipers. J. Chem. Ecol. 34, 1545-1552.

Mayland, H.F., Shewmaker, G.E., 2001. Animal health problems caused by silicon and other mineral imbalances. J. Range manage 54, 441-446.

Montes-Sánchez, J.J., Villalba, J.J., 2017a. Effects of early experience and alternative feeds on medusahead (Taeniatherum caput-medusae ssp. asperum) intake by sheep. Appl. Anim. Behav. Sci. 188, 9-16.

Montes-Sánchez, J.J., Villalba, J.J., 2017b. Understanding medusahead (Taeniatherum caput-medusae ssp. asperum) low intake and palatability through in vitro digestibility and fermentation kinetics. Animal 11, 1930-1938.

Montes-Sánchez, J.J., Van Miegroet, H., Villalba, J.J., 2017. Effects energy supplementation and time on use of medusahead by grazing ewes and their lambs. Rangeland Ecol. Manag. 70, 380-387.

Mote, T.E., Villalba, J.J., Provenza, F.D., 2007. Relative availability of tannin-and terpene-containing foods affects food intake and preference by lambs. J. Chem. Ecol. 33, 1197-1206.

Murphy, A.H., Turner, D., 1959. A study on the germination of medusahead seed. Bulletin $48,6-10$.

Pennings, S.C., Nadeau, M.T., Paul, V.J., 1993. Selectivity and growth of the generalist herbivore Dolabella auricularia feeding upon complementary resources. Ecology 74, 879-890.

Provenza, F.D., 1996. Acquired aversions as the basis for varied diets of ruminants foraging on rangelands. J. Anim. Sci. 74, 2010-2020.

Provenza, F.D., Villalba, J.J., 2006. Foraging in domestic herbivores: linking the internal and external milieu, 2019internal and external milieu. In: Bels, V.L. (Ed.), Feeding in Domestic Vertebrates: From Structure to Function. CABI Publ, Oxfordshire, UK, pp. 210-240.

Provenza, F.D., Burritt, E.A., Clausen, T.P., Bryant, J.P., Reichardt, P.B., Distel, R.A., 1990. Conditioned flavor aversion: a mechanism for goats to avoid condensed tannins in blackbrush. Am. Nat. 136, 810-828.

Provenza, F.D., Villalba, J.J., Bryant, J.P., 2003. Foraging by herbivores: linking the biochemical diversity of plants to herbivore culture and landscape diversity. In: Bissonette, J.A., Storch, I. (Eds.), Landscape Ecology and Resource Management. Linking Theory With Practice. Island Press, Washington, D.C. U.S.A, pp. 387-421.

Rapport, D.J., 1980. Optimal foraging for complementary resources. Am. Nat. 116, $324-346$.

Robbins, C.T., Hanley, T.A., Hagerman, A.E., Hjeljord, O., Baker, D.L., Schwartz, C.C., Mautz, W.W., 1987. Role of tannins in defending plants against ruminants: reduction in protein availability. Ecology 68, 98-107.

Robbins, C.T., Spalinger, D.E., van Hoven, W., 1995. Adaptation of ruminants to browse and grass diets: are anatomical-based browser-grazer interpretations valid? Oecologia 103, 208-213.

Rolls, B.J., 1986. Sensory-specific satiety. Nutr. Rev. 44, 93-101.

Saura-Calixto, F., Goñi, I., Mañas, E., Abia, R., 1991. Klason lignin, condensed tannins and resistant protein as dietary fibre constituents: determination in grape pomaces. Food Chem. 39, 299-309.

Van Keulen, J., Young, B.A., 1977. Evaluation of acid-insoluble ash as a natural marker in ruminant digestibility studies. J. Anim. Sci. 44, 282-287.

Van Soest, P.J., 2006. Rice straw, the role of silica and treatments to improve quality. Anim. Feed Sci. Technol 130, 137-171.

Van Soest, P.J., Jones, L.H.P., 1968. Effect of silica in forages upon digestibility. J. Dairy Sci. 51, 1644-1648.

Van Soest, P.V., Robertson, J.B., Lewis, B.A., 1991. Methods for dietary fiber, neutral detergent fiber, and nonstarch polysaccharides in relation to animal nutrition. J. Dairy Sci. 74, 3583-3597.

Villalba, J.J., Burritt, E.A., 2015. Intake of medusahead by sheep: influence of supplements, silica and individual animal variation. Invasive Plant Sci. Mana. 8, 151-159.

Villalba, J.J., Provenza, F.D., 2000a. Roles of flavor and reward intensities in the acquisition and generalization of food preferences: do strong plant signals always deter herbivory? J. Chem. Ecol. 26, 1911-1922.

Villalba, J.J., Provenza, F.D., 2000b. Roles of novelty, generalization, and postingestive feedback in the recognition of foods by lambs. J. Anim. Sci. 78, 3060-3069.

Westoby, M., 1978. What are the biological bases of varied diets? Am. Nat. 112, 627-631.

Young, J.A., 1992. Ecology and management of medusahead (Taeniatherum caputmedusae ssp. Asperum [Simk.] Melderis). Great Basin Nat. 52, 245-252.

Yu, J., Ahmedna, M., 2013. Functional components of grape pomace: their composition, biological properties and potential applications. Int. J. Food Sci. Technol. 48, 221-237.

Zimmerman, J.R., Johnson, W.S., Eiswerth, M.E., 2002. Medusahead: Economic Impact and Control in Nevada. University of Nevada, Reno. 